\title{
A GENERAL METHOD FOR THE DETECTION OF ADDITIVE, DOMINANCE AND EPISTATIC COMPONENTS OF VARIATION III. $F_{2}$ AND BACKCROSS POPULATIONS
}

\author{
J. L. JINKS and JEAN M. PERKINS \\ Department of Genetics, University of Birminghom
}

Received 21.(ix).69

\section{INTRODUCTION}

KEARSEY AND Jinks (1968) have recently described an extension of the design III experiment of Comstock and Robinson (1952). The extended design, which is a triple test cross, has two advantages over the original in that it allows the detection of epistatic components of variation and under well defined circumstances its use is no longer confined to populations derived by randomly mating an $\mathrm{F}_{2}$ from two inbred lines. In the present paper the new design and analysis will be used to investigate the $\mathrm{F}_{2}$ and back-cross populations derived from two crosses between inbred varieties of Nicotiana rustica. The results of these analyses will be compared with previous ones based on more extensive, alternative breeding programmes.

\section{SOURCE OF DATA}

The design III and triple test cross experiments analysed in this paper are summarised in table 1 . The $\mathrm{F}_{2}$ and first back-cross families investigated by these experiments were obtained from crosses between varieties 1 and 5 , and 2 and 12 of the Birmingham collection of inbred lines (Mather and Vines, 1952). These two crosses were chosen because they represent the extremes found among the many crosses that have been investigated for the control of the two characters of primary interest, plant height and flowering time. Thus, in the generations derived from the cross $1 \times 5$, epistasis is a relatively minor component of variation that is detectable in some environments but not in others (Mather and Vines, 1952; Opsahl, 1956; Hill, 1966; Jinks and Perkins, 1969; Perkins and Jinks, 1970). In contrast to this, in the generations derived from the cross $2 \times 12$, epistasis is a major component of variation that is present in every environment in which they have been grown (Jinks, 1954, 1956; Jinks and Jones, 1958; Perkins and Jinks, unpublished).

Populations derived from the cross $1 \times 5$ have been investigated by a design III crossing programme, in which each individual in the population sample is back-crossed to inbred lines 1 and $5\left(\mathrm{P}_{1}\right.$ and $\left.\mathrm{P}_{5}\right)$, on six occasions (table 1). On four of these occasions (marked * in table 1) the full triple test cross programme, in which each individual crossed to $P_{1}$ and $P_{5}$ is also crossed to the $F_{1}\left(P_{1} \times P_{5}\right)$, was carried out. On the three occasions on which $\mathrm{F}_{2}$ populations of the cross $2 \times 12$ were investigated the full triple test cross programme was used.

Up to and including the experiment grown in 1956 the unit of randomisation within each replicate was a plot of five plants belonging to the same 
family (incomplete randomisation). After 1956 complete randomisation at the individual plant level was used for all the experiments included in table 1.

The size of the sample taken from the $\mathrm{F}_{2}$ or back-cross population varies from 14 to 50 , the $F_{2}$ samples in general being about the size of the two backcross samples combined when grown in the same season. This variation in sample size was dictated by other requirements of the experiments of which the design III and triple test cross families were but a small part.

TABLE 1

Source of data

Cross $1 \times 5$

Experimental Design

Season Generation $\begin{gathered}\text { Sample } \\ \text { size }(n)\end{gathered} \overbrace{\text { Replications }(r)}$ Family size $(m)$ Randomisation

Source

\begin{tabular}{|c|c|c|c|c|c|c|}
\hline \multirow[t]{2}{*}{1946} & $\mathrm{~B}_{5}$ & 15 & 2 & 5 & incomplete & $\begin{array}{l}\text { Mather and } \\
\text { Vines, } 1952\end{array}$ \\
\hline & $\mathrm{B}_{1}$ & 15 & 2 & 5 & incomplete & $\begin{array}{l}\text { Mather and } \\
\text { Vines, } 1952\end{array}$ \\
\hline 1954 & $* F_{2}$ & 50 & 2 & 5 & incomplete & Opsahl, 1956 \\
\hline \multirow{2}{*}{1960} & $\mathrm{~B}_{5}$ & 15 & 3 & 5 & complete & Hill, 1966 \\
\hline & $B_{1}$ & 15 & 3 & 5 & complete & Hill, 1966 \\
\hline \multirow[t]{2}{*}{1961} & $\mathrm{~B}_{5}$ & 45 & 2 & 5 & complete & Hill, 1966 \\
\hline & $\mathrm{B}_{1}$ & 48 & 2 & 5 & complete & Hill, 1966 \\
\hline \multirow[t]{2}{*}{1962} & $\mathrm{~B}_{5}$ & 30 & 2 & 5 & complete & Hill, 1966 \\
\hline & $\mathrm{B}_{1}$ & 34 & 2 & 5 & complete & Hill, 1966 \\
\hline \multirow[t]{3}{*}{1965} & $* \mathrm{~B}_{5}$ & 14 & 2 & 5 & complete & $\begin{array}{l}\text { Perkins and } \\
\text { Jinks, } 1970\end{array}$ \\
\hline & $* \mathrm{~B}_{1}$ & 14 & 2 & 5 & complete & $\begin{array}{l}\text { Perkins and } \\
\text { Jinks, } 1970\end{array}$ \\
\hline & ${ }^{*} \mathrm{~F}_{2}$ & 40 & 2 & 5 & complete & $\begin{array}{l}\text { Perkins and } \\
\text { Jinks, } 1970\end{array}$ \\
\hline \multicolumn{7}{|c|}{ Cross $2 \times 12$} \\
\hline 1956 & ${ }^{*} \mathrm{~F}_{2}$ & 43 & 3 & 5 & incomplete & Breese, unpubl. \\
\hline 1969 I & ${ }^{*} \mathrm{~F}_{2}$ & 18 & 2 & 5 & complete & $\begin{array}{l}\text { Perkins and } \\
\text { Jinks, unpubl. }\end{array}$ \\
\hline II & ${ }^{*} \mathrm{~F}_{2}$ & 18 & 2 & 5 & complete & $\begin{array}{c}\text { Perkins and } \\
\text { Jinks, unpubl. }\end{array}$ \\
\hline
\end{tabular}

\section{Statistical ANALYses AND MODELS}

Following Kearsey and Jinks (1968) and Jinks, Perkins and Breese (1969) we will denote the cross between the $i$ th individual from the $\mathrm{F}_{2}$ or backcross population and the inbred parent with the higher score by $\mathrm{L}_{1}$, the corresponding cross with the other parent by $\mathrm{L}_{2 i}$ and the cross to the $\mathrm{F}_{1}$ by $\mathrm{L}_{3 i}$. The presence of epistasis may be detected where all three kinds of crosses are made by the method described by Kearsey and Jinks (1968). In the absence of epistasis, additive and dominance components of variation may then be estimated by the method of Comstock and Robinson (1952). Where, as in design III, the cross to the $F_{1}$ is not made, no test for epistasis is possible and the additive and dominance components estimated by the procedures of Comstock and Robinson will be biased in the presence of undetected epistasis.

Where all three kinds of crosses are made an alternative analysis is possible in which all comparisons among the three kinds of drogeny means 
(denoted by $\mathrm{L}_{1}, \mathrm{~L}_{2}$, and $\mathrm{L}_{3 i}$ ) are orthogonal to one another. These are:

$\begin{array}{ccrcl}\text { Comparison } & \mathrm{L}_{1} & \mathrm{~L}_{2 i} & \mathrm{~L}_{3 i} & \text { Testing for: } \\ 1 & 1 & 1 & 1 & \text { Additive component } \\ 2 & 1 & -1 & & \text { Dominance component } \\ 3 & 1 & 1 & -2 & \text { Epistatic component }\end{array}$

The variance of comparison 2 over all $n$ sets of progeny families $(i=1$ to $n$ ) is used to detect and estimate the dominance component of variation in the original analysis of Comstock and Robinson (1952) and in the modified analysis of Kearsey and Jinks (1968). Similarly, the squared deviations of comparison 3 summed over all $n$ sets is used to detect an epistatic component of variation in the analysis proposed by Kearsey and Jinks (1968). The variance of comparison 1 over the $n$ sets detects and estimates the additive component of variation but it differs from the comparable statistic in the original analysis which is based on $\mathrm{L}_{1} t$ and $\mathrm{L}_{2 t}$ (Kearsey and Jinks, 1968). The new analysis has two advantages. First, all items in the analysis are orthogonal and second, in the absence of epistasis the $\mathrm{L}_{3} t$ families are used to estimate the remaining components of variation instead of being discarded.

In the absence of epistasis the estimation of the additive and dominance components of variation now proceeds as follows (see Kearsey and Jinks, 1969, table 2).

\begin{tabular}{lcc}
\multicolumn{1}{c}{ Item } & d.f. & E.M.S. \\
Sums $\left(\mathrm{L}_{1 i}+\mathrm{L}_{2 i}+\mathrm{L}_{3} i\right)$ & $n-1$ & $\sigma^{2}+3 r \sigma_{m}^{2}$ \\
Differences $\left(\mathrm{L}_{1 i}-\mathrm{L}_{2 i}\right)$ & $n-1$ & $\sigma^{2}+2 r \sigma_{m l}^{2}$ \\
Error & $n(r-1)$ & $\sigma^{2}$
\end{tabular}

For the $\mathrm{F}_{2}$ and summed items from the two back-cross populations the expectation for $\sigma_{m}^{2}$ and $\sigma_{m l}^{2}$ in the absence of epistasis are:

$$
\begin{aligned}
& \text { No }\left\{\begin{array}{l}
\sigma_{m}^{2}=\frac{1}{8} \Sigma d^{2} \\
\sigma_{m l}^{2}=\frac{1}{8} \Sigma h^{2} .
\end{array}\right. \\
& \text { linkage }\left\{\begin{array}{l}
\sigma_{m}^{2}=\frac{1}{8} \Sigma d^{2} \pm \frac{1}{4} \Sigma\left(1-2 p_{j k}\right) d_{j} d_{k} \\
\sigma_{m l}^{2}=\frac{1}{8} \Sigma h^{2}+\frac{1}{4} \Sigma\left(1-2 p_{j k}\right) h_{j} h_{k} .
\end{array}\right.
\end{aligned}
$$

In the absence of linkage $D$, the additive component of variation, equals $\Sigma d^{2}$ and $\mathrm{H}$, the dominance component, equals $\Sigma h^{2}$. In the presence of linkage $\mathrm{D}$ equals $\Sigma d^{2} \pm 2 \Sigma\left(1-2 p_{j k}\right) d_{j} d_{k}$, where the + is for coupling linkages and the - for repulsion linkages and $p_{j k}$ is the recombination between the $j$ th and $k$ th loci, and $H$ equals $\Sigma h^{2}+2 \Sigma\left(1-2 p_{j k}\right) h_{j} h_{k}$.

In the simple analysis of variance used for illustration there is a single estimate of the error variance $\left(\sigma^{2}\right)$ obtained from replicates for testing the significance of sums $\left(\sigma_{m}^{2}\right)$ and differences $\left(\sigma_{m l}^{2}\right)$. However, the experimental designs described earlier provide a number of estimates of the error variance which will not necessarily be homogeneous and hence may not always be pooled to give a single estimate. Both the plot design and the completely randomised design provide estimates of the interactions between sums $\left(\mathrm{L}_{1} t+\mathrm{L}_{2} t+\mathrm{L}_{3} t\right)$ and differences $\left(\mathrm{L}_{1} t-\mathrm{L}_{2} i\right)$ with replicate blocks. They also provide estimates of the mean variance within families, within replicate blocks, which for the plot design will also be the variance within plots. If 
the mean within family (or within plot) variances of the $\mathrm{L}_{1 \ell}$ and $\mathrm{L}_{2}$ types of families do not differ significantly from that of the $\mathrm{L}_{3 i}$ families, all may be pooled to give an error for testing the block interactions of sums and differences. If, however, they differ significantly the variances may be pooled over $\mathrm{L}_{1 i}$ and $\mathrm{L}_{2 i}$ types of families to give an error for testing the interaction of blocks and differences and the variances of all three types of families may be pooled to give the error for testing the corresponding interaction with sums.

If the block interactions are not significant when tested against the appropriate within family, within block variance they may be pooled with the latter to provide an error for testing the main effects (sums and differences). If, however, the interactions are significant, the sums and differences items must be tested against the corresponding block interaction.

\section{RESUlts}

\section{(i) Tests for epistasis}

The method for detecting epistasis will be illustrated by the 1965 final height data for the $F_{2}$ of the cross $1 \times 5$ (table 1$)$. In these data the sample size, $n$ equals 40 ; two replicate blocks were grown, each replicate containing five completely randomised plants of each of the three kinds of progeny families $\left(L_{1} i, L_{2} i\right.$, and $L_{3}$ ) in each of the 40 sets. Each family in each replicate provides a within family variance for four degrees of freedom and since there are 120 such families in each replicate $(40 \times 3)$ the mean variance within families has a total of 960 degrees of freedom. In these data it is reduced to 951 due to the loss of nine plants.

The 40 replicated sets of progeny families provide 40 replicate values of $\left(\mathrm{L}_{1}+\mathrm{L}_{2 i}-2 \mathrm{~L}_{3 i}\right)$ where $i=1$ to 40 . There are, therefore, 40 degrees of freedom for the summed squared values of $\left(\mathrm{L}_{1 i}+\mathrm{L}_{2 i}-2 \mathrm{~L}_{3 i}\right)$ after summing over replicates and 40 degrees of freedom for the summed squared differences between replicate values. The mean squares corresponding with these two items and the mean variance within families, adjusted to correpond with the means of families of five plants, are given in table 2(a). It is quite clear from this analysis that there is neither evidence of epistasis nor of differences between replicates in this respect.

We can, however, pursue the analysis further in the way described by Perkins and Jinks (1970). Thus the epistasis sum of squares for 40 degrees of freedom can be subdivided into an item for one degree of freedom testing the mean value of the epistatic term $\left(\mathrm{L}_{1 i}+\mathrm{L}_{2 i}-2 \mathrm{~L}_{3 i}\right)$ over all 40 sets of progeny families and an item for 39 degrees of freedom for the remainder which test variation in the value of the epistatic term over the 40 sets of families around this mean value. The sum of squares of replicates for 40 degrees of freedom can also be partitioned into corresponding items for one and 39 degrees of freedom respectively. The value of this further partitioning is that for $\mathrm{F}_{2}$ populations the overall epistatic item tests for $i$ type epistasis (homozygote $\times$ homozygote interactions) and the variation among sets tests for $j$ and $l$ types of epistasis (homozygote $\times$ heterozygote and heterozygote $\times$ heterozygote interactions, respectively). This analysis and its interpretation, which are described by Perkins and Jinks (1970), do not separate the kinds of epistasis in such a clear way for back-cross populations. The outcome of applying this further analysis to the present data is shown in 
table 2(b). The analysis confirms the absence of both classes of epistasis. Had the replicate item or the replicate $\times$ epistasis item been significant these would have been the appropriate errors for testing the significance of the overall epistasis and epistasis items, respectively, as variance ratios.

\section{TABLE 2}

Analysis of variance to test for epistasis for final height in the $F_{2}$ population of the cross $1 \times 5$ grown in 1965

(a)

\begin{tabular}{|c|c|c|}
\hline Item & d.f. & M.S. \\
\hline $\begin{array}{l}\text { Epistasis }\left(\mathrm{L}_{1 i}+\mathrm{L}_{2 i}-2 \mathrm{~L}_{3 i}\right) \\
\text { Replicates } \\
\text { Within families within replicates }\end{array}$ & $\begin{array}{r}40 \\
40 \\
951\end{array}$ & $\begin{array}{l}6 \cdot 49 \\
6 \cdot 78 \\
5 \cdot 64\end{array}$ \\
\hline Item & d.f. & M.S. \\
\hline $\begin{array}{l}\text { Overall epistasis }(i \text { type }) \\
\text { Epistasis }(j \text { and } l \text { type }) \\
\text { Replicates } \\
\text { Epistasis } \times \text { replicates } \\
\text { Within families within replicates }\end{array}$ & $\begin{array}{r}1 \\
39 \\
1 \\
39 \\
951\end{array}$ & $\begin{array}{r}1 \cdot 69 \\
6 \cdot 61 \\
21 \cdot 46 \\
6 \cdot 40 \\
5 \cdot 64\end{array}$ \\
\hline
\end{tabular}

N.S. = not significant.

The results of applying these analyses to all the triple test cross sets of data listed in table 1 are summarised in table 3 . In a general way these results agree with previous analyses in suggesting that epistasis is a more important component of variation for the cross $2 \times 12$ than for the cross $1 \times 5$. Further comment will be deferred until the analysis of the additive and dominance components has been described.

TABLE 3

The results of applying the tests for epistasis to the triple test cross data

\begin{tabular}{|c|c|c|c|c|c|c|}
\hline \multirow[b]{2}{*}{ Cross } & \multirow[b]{2}{*}{ Season } & \multirow[b]{2}{*}{ Population } & \multicolumn{2}{|c|}{ Flowering time } & \multicolumn{2}{|c|}{ Final height } \\
\hline & & & $\begin{array}{l}\text { Overall } \\
\text { epistasis }\end{array}$ & Epistasis & $\begin{array}{l}\text { Overall } \\
\text { epistasis }\end{array}$ & Epistasis \\
\hline $1 \times 5$ & $\begin{array}{l}1954 \\
1965 \\
1965\end{array}$ & $\begin{array}{l}F_{2} \\
B_{5} \\
B_{1} \\
F\end{array}$ & $\begin{array}{l}\text { N.S. } \\
\text { N.S. } \\
\text { N.S. }\end{array}$ & $\begin{array}{l}\text { N.S. } \\
\text { N.S. } \\
* * *\end{array}$ & $\begin{array}{l}\text { N.S. } \\
\text { N.S. } \\
\text { N.S. }\end{array}$ & $\begin{array}{l}\text { N.S. } \\
\text { N.S. }\end{array}$ \\
\hline $2 \times 12$ & $\begin{array}{l}1965 \\
1956\end{array}$ & $\begin{array}{l}\mathrm{F}_{2} \\
\mathrm{~F}_{9}\end{array}$ & $\begin{array}{l}* * \\
* *\end{array}$ & N.S. & $\underset{* *}{\text { N.S. }}$ & N.S. \\
\hline & $1969 \mathrm{I}$ & $\mathrm{F}_{2}$ & $*$ & N.S. & N.S. & N.S. \\
\hline & 1969II & $F_{2}$ & N.S. & $*$ & $*$ & $*$ \\
\hline
\end{tabular}

(ii) Estimation of additive and dominance components

Where epistasis is absent we may proceed with the analysis of the additive and dominance components of variation as outlined in section 3. Again we will use the 1965 final height data for the $F_{2}$ population for illustrating the procedures.

There are 40 values of the sum $\left(\mathrm{L}_{1 i}+\mathrm{L}_{2 i}+\mathrm{L}_{3 i}\right)$ for each of two replicates. 
Hence there are 39 degrees of freedom for the variance of these sums, 1 degree of freedom for replicates and 39 for the interaction of replicates and sums. Similarly, there are 40 values of the difference $\left(\mathrm{L}_{1}-\mathrm{L}_{2}\right)$ for each of two replicates so that there are 39 degrees of freedom for the variance of these differences, 1 degree of freedom for comparing the mean difference over all 80 values, and 39 degrees of freedom and one, respectively, for the interactions of each of these with replicates. Again we have 951 degrees of freedom for the mean variance within the 120 replicated families and this is the appropriate error variance for the analysis of sums. The mean within

TABLE 4

Analysis of variance to detect additive and dominance components for final height in the $F_{2}$ population of the cross $1 \times 5$ grown in 1965

\begin{tabular}{|c|c|c|c|}
\hline Item & d.f. & M.S. & $\chi^{2}(4)$ \\
\hline \multicolumn{4}{|l|}{ Analysis of sums $\left(\mathrm{L}_{1 i}+\mathrm{L}_{2 i}+\mathrm{L}_{3 i}\right)$} \\
\hline 1. Replicates & 1 & $32 \cdot 78$ & $*$ \\
\hline 2. Sums (Additive component) & 39 & $28 \cdot 66$ & *** \\
\hline 3. $2 \times$ Replicates & 39 & $6 \cdot 19$ & N.S. \\
\hline 4. Within families & 951 & $5 \cdot 64$ & N.S. \\
\hline \multicolumn{3}{|l|}{ Analysis of differences $\left(L_{1 i}-L_{2 i}\right)$} & $\chi^{2}(9)$ \\
\hline $\begin{array}{l}\text { 5. Between inbred parents } \\
\text { 6. Differences (Dominance }\end{array}$ & 1 & $1423 \cdot 85$ & $* * *$ \\
\hline component) & 39 & 7.05 & N.S. \\
\hline 7. $5 \times$ Replicates & 1 & $1 \cdot 17$ & N.S. \\
\hline 8. $6 \times$ Replicates & 39 & $5 \cdot 70$ & N.S. \\
\hline 9. Within families & 635 & $5 \cdot 01$ & N.S \\
\hline
\end{tabular}

family variance of the $\mathrm{L}_{1}$ and $\mathrm{L}_{2 t}$ types of families, however, differ significantly from that of the $\mathrm{L}_{3 i}$ families. For the analysis of differences, therefore, the appropriate error term is the mean within family variance of the $\mathrm{L}_{1 \imath}$ and $\mathrm{L}_{2 t}$ families. This should have 640 degrees of freedom but these are reduced to 635 due to the loss of 5 plants.

The nine items of this analysis, divided into two parts, the analysis of sums and the analysis of differences, are given in table 4. All mean squares are appropriate to an analysis of the means of families of size five. None of the replicate interactions is significant hence the within family variances are the appropriate errors for testing the significance of the main items. On this test the sums item is significant but the difference item is not. Hence there is evidence of an additive, but not of a dominance, component of variation.

In the absence of replicate interactions the relevant mean squares for estimating the genetic components of variation reduce to:

\begin{tabular}{lrrc}
\multicolumn{1}{c}{ Items } & d.f. & M.S. & Expected M.S. \\
Sums & 39 & 28.66 & $\sigma_{e 1}^{2}+6 \sigma_{m}^{2}$ \\
Pooled error & 999 & 5.65 & $\sigma_{e 1}^{2}$ \\
Differences & 39 & 7.05 & $\sigma_{e 2}^{2}+4 \sigma_{m l}^{2}$ \\
Pooled error & 674 & 5.01 & $\sigma_{e 2}^{3}$
\end{tabular}

From the expected mean squares (see section 3 ) we obtain the estimates:

$$
\begin{aligned}
6 \hat{\sigma}_{m}^{2} & =23.01=6 \times \frac{1}{8} \hat{\mathrm{D}} \\
\text { and } 4 \hat{\sigma}_{m l}^{2} & =2.04=4 \times \frac{1}{8} \hat{\mathrm{H}},
\end{aligned}
$$


therefore:

$$
\begin{aligned}
& \hat{D}=30.69 \\
& \hat{H}=4.08 .
\end{aligned}
$$

The estimate of $D$ is, of course, highly significant (table 4) but the estimate of $\mathrm{H}$ does not differ significantly from zero, $\mathrm{D}$ and $\mathrm{H}$ having the expectations given in section 3 in the absence and presence of linkage, respectively.

One further useful parameter may be extracted from these data, namely, $\mathrm{F}$, which is the $\Sigma d h$ in the absence of linkage and some function of this in its presence. F may be estimated as the covariance of sums and differences and its significance determined as the correlation of sums and differences (Jinks, Perkins and Breese, 1969). For the $1965 \mathrm{~F}_{2}$ data, $\mathrm{F}=+0.41$ and is non-significant. This result means that either there is no dominance or the dominance is ambidirectional.

TABLE 5

Estimates of $D, H$ and $F$ and their significance levels for all sets of data. The presence of epistasis has been detected for the estimates in italics but not for the estimates in bold face (see table 3)

Cross $1 \times 5$

Season population
$1946\left(\mathbf{B}_{1}+\mathbf{B}_{5}\right)$
$1954 \mathbf{F}_{\mathbf{2}}$
$1960\left(\mathbf{B}_{1}+\mathbf{B}_{6}\right)$
$1961\left(\mathbf{B}_{1}+\mathbf{B}_{6}\right)$
$1962\left(\mathbf{B}_{1}+\mathbf{B}_{6}\right)$
$1965\left(\mathbf{B}_{1}+\mathbf{B}_{6}\right)$
$\mathbf{F}_{\mathbf{2}}$

Cross $2 \times 12$

$1956 \mathrm{~F}_{2}$ $19691 \mathrm{~F}_{\mathrm{a}}$ $196911 F_{2}$

\begin{tabular}{|c|c|c|}
\hline $\mathrm{D}$ & $\mathrm{H}$ & $\mathbf{F}$ \\
\hline $12 \cdot 46 * * *$ & $4 \cdot 28 *$ & -0.9 \\
\hline $83 \cdot 28 * *$ & $15 \cdot 48$ & $2 \cdot 0$ \\
\hline $13.89 * * *$ & $25 \cdot 11 * * *$ & -0.3 \\
\hline $64 \cdot 16 * * *$ & $2 \cdot 88$ & -0.46 \\
\hline $28 \cdot 40^{* *}$ & $8 \cdot 56^{*}$ & 1.5 \\
\hline $26 \cdot 87 *$ & $7 \cdot 34 * *$ & 0.1 \\
\hline $25.95 * * *$ & $7 \cdot 40^{*}$ & 0.2 \\
\hline
\end{tabular}

Flowering time

\begin{tabular}{|c|c|c|}
\hline D & $\mathrm{H}$ & $\mathbf{F}$ \\
\hline $28.58 * * *$ & $11 \cdot 92 * *$ & $1 \cdot 40$ \\
\hline $32 \cdot 39 * * *$ & $10 \cdot 00$ & $-2 \cdot 13$ \\
\hline $46 \cdot 24 * * *$ & $49 \cdot 01 * * *$ & $-11 \cdot 12^{* *}$ \\
\hline $65.88 * * *$ & $6 \cdot 56^{* *}$ & -1.09 \\
\hline $22 \cdot 54$ & $1 \cdot 60$ & -1.94 \\
\hline $53.55 * * *$ & $7 \cdot 16^{*}$ & -0.06 \\
\hline $30 \cdot 69 * * *$ & 4.08 & 0.41 \\
\hline
\end{tabular}

Final height

The analyses described so far are appropriate when the triple test cross design has been used. For those experiments where the North Carolina III design has been used (see section 2) the test for epistasis is not applicable and additive and dominance components may be detected and estimated, assuming no epistasis, using the standard design III analysis as described by Kearsey and Jinks (1968).

The estimates of $\mathrm{D}, \mathrm{H}$ and $\mathrm{F}$ for all sets of data derived from either the triple test cross analysis or the design III analysis are given in table 5 along with their significance levels. Where the test for epistasis has revealed its presence, the estimates are given in italics, where the same tests have detected no epistasis, the estimates are given in bold face. For the remaining estimates no test for epistasis has been possible because design III was used.

\section{(i) Gene action}

\section{INTERPRETATION}

Reference to the estimates of $\mathrm{H}$ and $\mathrm{F}$ in table 5, shows that for flowering time and final height in the cross $1 \times 5$ there is no evidence of a dominance component of variation in the data $\left(1954 \mathrm{~F}_{2}\right.$ for both characters and $1965 \mathrm{~F}_{2}$ for final height) where there is no epistatic component of variation. On the 
other hand, there is evidence of an additive component of variation irrespective of the presence of epistasis. It seems likely, therefore, that either the few significant estimates of the $\mathrm{H}$ and $\mathrm{F}$ components arise from the bias introduced into these estimates by the presence of epistasis or that dominance and epistasis arise simultaneously in response to the same environmental factors. Since $\mathrm{F}$ is both small in magnitude relative to $\mathrm{D}$ and $\mathrm{H}$ and in all except one instance non-significant, any dominance, or epistasis confounded with the dominance, cannot have much of a directional element.

For the cross $2 \times 12$ there is a test for dominance unbiased by a significant epistatic component of variation only for final height in 1969, environment I. For these data there is a significant dominance component with a significant directional element even when epistasis is absent. Hence it looks as though dominance and epistasis play a greater role in most seasons for this cross than for the cross $1 \times 5$ and that there is a more marked directional element both for the dominance component and for the epistatic component which is confounded with it in most environments.

\section{(ii) Genotype-environmental interactions}

In the absence of interactions between the additive, dominance and epistatic actions of the genes and the environments in which the plants were grown, the estimates of $\mathrm{D}, \mathrm{H}$ and $\mathrm{F}$ should be the same in each season and location and the test for epistasis should always give the same result. In the presence of genotype-environmental interactions the estimates of $\mathrm{D}, \mathrm{H}$ and $\mathrm{F}$ may differ over environments in one of two ways. For example, if all kinds of gene action are equally sensitive to the environmental differences the estimates of $\mathrm{D}, \mathrm{H}$ and $\mathrm{F}$ will change at the same rate from one environment to another. This will be true irrespective of whether or not the estimates of $\mathrm{D}, \mathrm{H}$ and $\mathrm{F}$ are confounded with epistatic components of variations. If, on the other hand, the different kinds of gene action are not equally sensitive to the environmental differences the estimates of $\mathrm{D}, \mathrm{H}$ and $\mathrm{F}$ will change to different extents over the environments.

The triple test cross and design III experiments provide a unique opportunity for making these comparisons over environments because unlike the estimates of the parameters obtained from other designs the estimates they provide are uncorrelated and have similar or identical sampling errors. Hence correlated changes in the estimates or different rates of change cannot arise solely as a result of correlated sampling errors or unequal sampling errors.

For flowering time in the cross $1 \times 5$ the estimates of $\mathrm{D}$ and $\mathrm{H}$ range from 12.46 and 4.28 in 1946 to 113.89 and 25.11 in 1960 (table 5) and they do so in a correlated way. However, over all the environments $\mathrm{D}$ changes at approximately four times the rate of change of $\mathrm{H}$. To put it another way the ratio of $\mathrm{H}$ to $\mathrm{D}$ (the square of the dominance ratio) falls as $\mathrm{D}$ increases. The estimates of $\mathrm{F}$ are not significant in any environment and they change relatively little with the environment. From the one environment in which epistasis is known to be present (1965, table 3 ) and the one environment in which it is known to be absent (1954) it is clear that the epistatic component is larger in the environment in which the estimates of $\mathrm{D}$ and $\mathrm{H}$ are the smaller (table 4). It appears, therefore, that the additive and dominance action of the genes respond in a similar way to the different environments but that the additive action responds at a greater rate. The epistatic action 
of the genes, however, responds in a different way to the environmental stimuli.

Final height in the same cross presents a similar picture. The estimates of $\mathrm{D}$ range from 22.54 in 1962 to 65.88 in 1961 while those of $\mathrm{H}$ range from 1.60 in 1962 to 49.01 in 1960 (table 5). However, apart from the latter value of $\mathrm{H}$ there is virtually no variation in its magnitude over environments. There is similarly no variation in the estimates of $\mathrm{F}$ apart from the single significant value in 1960 . There is also less variation in the magnitude of the epistatic component between the two seasons where its presence can be investigated (table 3). Thus there is no evidence of its presence in 1954 and borderline significance for its presence in one of the three populations which were tested in 1965. Overall, therefore, the dominance and epistatic gene action appear to be less sensitive to the environmental differences than the additive action of the genes.

For flowering time in the cross $2 \times 12$ the situation is again similar, D, $\mathrm{H}$ and $\mathrm{F}$ showing correlated changes over the three environments (table 5). The estimates of $\mathrm{D}$, however, change at about twice the rate of $\mathrm{H}$ and four times the rate of $F$. The magnitude of the epistatic component also shows a correlation with the changes in $\mathrm{D}, \mathrm{H}$ and $\mathrm{F}$. Thus all three kinds of gene action respond in a similar way to the environmental differences but the additive action is again the most sensitive.

Final height also shows highly correlated changes in the magnitudes of $\mathrm{D}, \mathrm{H}, \mathrm{F}$ and the epistatic component. For this character, however, the estimates of $\mathrm{D}$ and $\mathrm{H}$ change at almost the same rate and only $\mathrm{F}$ changes at a lower rate. Hence, there is less evidence of a differential sensitivity of the different kinds of gene action to the environment for final height.

\section{(iii) Comparison with earlier results}

The contributions of the various genetic, environmental and genotypeenvironmental interaction components to the variation in flowering time and final height observed among the generations derived from the cross $1 \times 5$ have been studied over many years by numerous alternative experimental designs and breeding programmes. The cumulative results have recently been analysed and reviewed by Bucio Alanis, Perkins and Jinks (1969), Jinks and Perkins (1969) and Perkins and Jinks (1970).

The results of the triple test crosses and design III experiments agree in all important respects with these earlier studies. They agree, for example, in showing that the additive component of variation and its interaction with the environment are the largest sources of variation. They also agree in showing that the non-additive sources of variation, dominance and epistasis, are relatively less important and show a lower sensitivity to environmental sources of variation.

Previous studies of the cross $2 \times 12$ are rather limited (Jinks, 1954, 1956; Jinks and Jones, 1958), nevertheless they have established the importance of the dominance and epistatic components as well as of the additive component. They have also shown a marked directional element to the nonadditive components. All these conclusions are supported by the analysis of the triple test crosses.

Using a complex breeding programme that yielded information from 21 generations derived from the cross $1 \times 5$ it has recently been possible to detect linkage among the genes controlling flowering time and final height 
(Jinks and Perkins, 1969; Perkins and Jinks, 1970). Although, as we have seen (section 3 ) the expectations of $\mathrm{D}$ and $\mathrm{H}$ in the triple test cross and design III experiments differ in the presence and absence of linkage, they do not provide a means of testing for linkage. There is, of course, one further statistic available, the mean variance within families, which has not been used to estimate the parameters in the biometrical model. This, however, would only allow us to estimate $\mathrm{E}_{1}$, using the values of $\mathrm{D}$ and $\mathrm{H}$ obtained from the variance components $\sigma_{m}^{2}$ and $\sigma_{m l}^{2}$ by assuming no linkage. We require, therefore, an independent estimate of $E_{1}$, such as could be obtained from the parental and $F_{1}$ generations, in order to test the assumption of no linkage. In the absence of epistasis, which can be tested by the triple test cross analysis, and of genotype-environmental interactions, which can be tested by the homogeneity of the variances within the parental and $F_{1}$ families, an unambiguous test for linkage is provided by comparing the observed within family variances of the triple test cross families with those predicted from the estimates of $\mathrm{D}, \mathrm{H}$ and $\mathrm{E}_{\mathrm{I}}$. When epistasis and genotypeenvironmental interactions are present an unambiguous test for linkage is provided by comparing the total variance of the $\mathrm{F}_{2} \times \mathrm{F}_{1}\left(\mathrm{~L}_{3} i\right)$ generation with that of the $F_{2}$ (Perkins and Jinks, 1970).

\section{SUMmary}

1. The advantages of the extended form of the design III experiment of Comstock and Robinson, which is a triple test cross, are illustrated by the analysis of design III and triple test cross experiments on the $F_{2}$ and first back-cross generations of crosses between inbred varieties 1 and 5 , and 2 and 12 of Nicotiana rustica grown in a number of environments.

2. A modification of the analysis of Kearsey and Jinks is proposed and illustrated which retains the advantages of the original but makes fuller use of the families in the triple test cross that have the $F_{1}$ as one parent.

3 . The results of the anlayses show the relative unimportance of dominance and epistasis compared with the additive component of variation for the characters plant height and flowering time in the cross $1 \times 5$ when grown in most environments. The non-additive components of variation, on the other hand, are an important element in the cross $2 \times 12$ in all environments.

4. Because the estimates of the components of variation obtained from either of the experimental designs have similar or identical sampling errors and are uncorrelated the variation in their absolute and relative values over environments can be unambiguously attributed to genotype-environmental interactions.

5. Comparisons over environments show that there are genotypeenvironmental interactions that are, in general, greater for the additive than for the non-additive action of the genes.

6. The results of these analyses compare favourably with the cumulative information from larger experiments on the same varieties using a number of alternative designs.

\section{REFERENCES}

BUCIO ALANIS, L., PERKINS, JEAN M., AND JINks, J. L. 1969. Environmental and genotypeenvironmental components of variability. V. Segregating generations. Heredity, 24, 115-127. 
COMSTOCK, R. E., AND ROBINSON, H. F. 1952. Estimation of average dominance of genes. Heterosis, Ch. 30. Iowa State College Press.

HILL, J. 1966. Recurrent back-crossing in the study of quantitative inheritance. Heredity, $21,85-120$.

JINKs, J. L. 1954. The analysis of continuous variation in a diallel cross of Nicotania rustica varieties. Genetics, 39, 767-788.

JiNks, J. L. 1956. The $\mathrm{F}_{2}$ and back-cross generations from a set of diallel crosses. Heredity, 10, 1-30.

JINKS, J. L., AND JONES, R. MORLEY. 1958. Estimation of the components of heterosis. Genetics, 43, 223-234.

JINKS, J. L., AND PERKINS, JEAN M. 1969. The detection of linked epistatic genes for a metrical trait. Heredity, 24, 465-475.

JINKS, J. L., PERKINS, JEAN M., AND BREESE, E. L. 1969. A general method of detecting additive, dominance and epistatic variation for metrical traits. II. Application to Inbred Lines. Heredity, 24, 45-57.

KEARSEY, M. J., AND JINKS, J. L. 1968. A general method of detecting additive, dominance and epistatic variation for metrical traits. I. Theory. Heredity, 23, 403-409.

MATHER, K., AND viNes, A. 1952. The inheritance of height and flowering time in a cross of Nicotiana rustica. Quantitative Inheritance (Ed. R. C. Reeve). C. H. Waddington, London. H.M.S.O., 49-80.

OPSAHL, B. 1956. The discrimination of interactions and linkage in continuous variation. Biometrics, 10, 415-432.

PERKINS, JEAN M., AND JINKs, J. L. 1970. Detection and estimation of genotype-environmental linkage and epistatic components of variation for a metrical trait. Heredity. 25, 157-177. 